\title{
Avaliação da qualidade no aeroporto de Marabá (Pará, Brasil): utilização de SERVQUAL, Modelo de Kano e QFD
}

\section{Quality evaluation at Marabá airport, Pará, Brasil: use of SERVQUAL, Kano Model and QFD}

\author{
Peri Guilherme Monteiro da Silva (SILVA, P. G. M. da) ${ }^{*}$; \\ Murilo Marques Menezes Nascimento (NASCIMENTO, M. M. M.) \\ Leonardo Augusto Lobato Bello (BELLO, L. A. L.)
}

RESUMO - Neste artigo se analisa a imposição de requisitos na prestação de serviços do aeroporto de Marabá, situado no sudeste do Pará, um dos estados que compõe o território brasileiro. Percebe-se o crescimento e participação constante do setor de serviços no Produto Interno Bruto - PIB brasileiro desta maneira as organizações focam-se em oferecer qualidade atrelada a seus serviços, não obstante, disto têm-se os aeroportos. Para alcance de entender qualidade segundo a demanda, utilizou-se no local de estudo a escala SERVQUAL, modelo de Kano e Desdobramento da Função Qualidade. O SERVQUAL identificando as lacunas entre a expectativa e a percepção dos usuários, modelo de Kano categorizando os atributos relevantes para a satisfação dos usuários e o QFD correlacionando os requisitos dos clientes com as características voltadas para o bem-estar dos clientes, a partir de seus anseios. A partir do resultado da pesquisa constatou-se a relevância de treinamento dos colaboradores e diminuição do tempo de espera como de suma importância a decisões voltadas a melhoria de qualidade.

Palavras-chave: Turismo, Aeroporto, Serviços; SERVQUAL; Kano Model; QFD.

ABSTRACT - This article analyzes the imposition of requirements in the rendering of services from Marabá airport, located in the southeast of Pará, one of the states that make up the Brazilian territory. The growth and constant participation of the service sector in the Gross Domestic Product - Brazilian GDP, in this way, the organizations are focused on offering quality linked to their services, nevertheless, this is the airports. In order to understand quality on demand, the SERVQUAL scale, Kano model and Quality Function Deployment were used at the study site. SERVQUAL identifying the gaps between user expectation and perception, Kano model categorizing the attributes

\footnotetext{
* Formação: Graduação em Engenharia de Produção pela Universidade do Estado do Pará (UEPA), Mestrando bolsista CAPES no Programa de Pós-graduação em Desenvolvimento e Meio Ambiente Urbano (PPDMU) da Universidade da Amazônia (UNAMA). Endereço Físico para correspondência: Avenida Alcindo Cacela, 278, Bairro Umarizal. CEP: 66065-205 - Belém - Pará - Brasil. E-mail: periguilherme@hotmail.com

** Formação: Graduação em Engenharia de Produção pela Universidade do Estado do Pará (UEPA). Endereço Físico para correspondência: Avenida Alcindo Cacela, 278, Bairro Umarizal. CEP: 66065-205 - Belém - Pará - Brasil. E-mail: murilo.marques.m@ hotmail.com

*** Formação: Mestrado e Doutorado em Engenharia Civil pela Pontifícia Universidade Católica (PUCRJ). Atividade profissional: Professor no Programa de Pós-graduação em Desenvolvimento e Meio Ambiente Urbano (PPDMU) da Universidade da Amazônia (UNAMA). Endereço Físico para correspondência: Avenida Alcindo Cacela, 278, Bairro Umarizal. CEP: 66065-205 - Belém - Pará Brasil. E-mail: leonardo.bello@unama.br
} 
relevant to user satisfaction, and QFD correlating customer requirements with the characteristics aimed at the well-being of the clients, from their yearnings. From the results of the research, the relevance of training of employees and decrease of waiting time was verified as being of paramount importance to decisions aimed at quality improvement.

Key words: Tourism; Airports; Services; SERVQUAL; Kano Model; QFD. 


\section{INTRODUÇÃO}

A qualidade de um serviço, independente de seu local de prestação deve objetivar-se em gerar satisfação ao cliente. Fato de suma importância para estabelecer uma imagem positiva de uma empresa dentro do mercado, ou seja, faz com que alcance grande fatia de mercado.

A ideia de serviços serem prestados com qualidade é fortalecida pelos números do Instituto Brasileiro de Geografia e Estatística (IBGE, 2018) que em sua ultima divulgação de pesquisa sobre serviços, revela diminuição da oscilação de receita nominal de serviços, sendo variação mês/mês de -3,1\% de dezembro2017/janeiro2018 e de $-0,2 \%$ de janeiro2018/fevereiro2018, continuamente informa alteração acumulada de $-2,4 \%$ na taxa de variação do volume de serviços acumulada de 12 meses até o mês de fevereiro de 2018 e analisando-se esta queda do setor de serviços, verifica-se a necessidade de oferecimento de serviços com qualidade.

Maia (2013) e Silva, Silva e Oliveira (2018) afirmam a busca em ritmo crescente dos clientes por serviços que atendam todas as suas expectativas culminando em representação de qualidade a cada consumidor. A interação empresa-cliente é considerada um serviço, ou seja, tem de apresentar neste quesito uma forma de entender a demanda e assim destacar-se perante a concorrência, pois se for realizada a análise correta do almejado pela clientela, as expectativas dos clientes serão atendidas.

Um aeroporto é um local de interação de cliente com a empresa, necessitando apresentar níveis considerados satisfatórios de qualidade. Mas o aeroporto também é significado de desenvolvimento de meio de transporte e interação entre espaço micro e macro, ou seja, tem-se este ambiente como um local de prestação de serviço e sinônimo de crescimento socioeconômico, isto influencia diretamente na necessidade de compreensão dos anseios de suas demandas em relação à prestação de serviços (SANTOS, 2001; ASCHER, 2010; GÜLLER 2002).

Devido às dimensões continentais que caracterizam o Brasil e seu crescimento econômico acelerado, é perceptível a crescente utilização de serviços de transportes aéreos, em consequência de este ser o meio de transporte mais rápido atualmente dentro do espaço nacional ligando grandes distâncias. A Agência Nacional de Aviação Civil (ANAC, 2017) informa o número de 2605 aeroportos funcionando oficialmente, ou 
seja, com toda a regulamentação respeitada sendo: 2026 privados e 579 públicos. Dentro do espaço do Estado do Pará (Brasil), existem 122 aeródromos particulares e 30 públicos, para o estudo foi escolhido o aeroporto da cidade de Marabá, situado no oeste paraense - tendo como justificativa: ser o terceiro mais movimentado no estado ficando atrás apenas das cidades de Belém e Santarém, sendo o principal aeroporto na região em que se situa.

Existem diversas formas de verificar como se apresentam os serviços aos clientes, uma delas é o modelo proposto por Parasuraman et al. (1988), o SERVQUAL - para quantificar onde ocorrem falhas na prestação de uma atividade e o modelo de Kano informado por Tontini (2007) que classifica todos os atributos almejados pela demanda em: obrigatório, unidimensional, neutro, atrativo e reverso.

Para realizar alcance de resultados mais aproximados dos anseios pela demanda, isto é, conseguir representar em dados os desejos de uma população, Cheng (2010) sugere a utilização do QFD - Quality Function Deployment, em português significa Desdobramento da Função Qualidade, ferramenta para certificar qualidade dentro de um processo ou em um produto, ou seja, é a ferramenta de planejamento da qualidade. Neste artigo se objetivou realizar a avaliação da qualidade dos serviços prestados no aeroporto da cidade de Marabá utilizando a escala SERVQUAL, modelo de Kano e Desdobramento da Função Qualidade.

\section{CARACTERIZAÇÃO E DELINEAMENTO DA PESQUISA}

A pesquisa realizada é caracterizada como descritiva, pois partiu em buscar descrever como a população amostral percebia determinada situação, entendendo que existe a possibilidade de variação das respostas de acordo com a diferença das regiões. Quanto à caracterização perante a natureza de resultados é considerada aplicada, devido ter como meta fazer a aplicação de duas ferramentas em determinada amostra, gerando conhecimento sobre problemas viventes.

Quando se refere à abordagem, existiu a união de quantitativa e qualitativa, ou seja, quanti-qualitativa, pois foi realizada aplicação de questionário onde os 
entrevistados alocaram valores referentes à suas análises e posteriormente esses dados foram analisados e tratados quantitativamente.

Os procedimentos técnicos existentes na pesquisa foram: a pesquisa bibliográfica, pois ocorreu o levantamento das teorias e dados em materiais existentes; Survey - Questionário para a amostragem responder com seu ponto de vista sobre os locais pesquisados, sem intervenção dos entrevistadores.

O desenvolvimento do projeto iniciou com pesquisa bibliográfica para alcançar conhecimento sobre os métodos utilizados: modelo de Kano, SERVQUAL e QFD. As ferramentas de Kano e SERVQUAL necessitam de respostas provenientes dos clientes. Foi utilizada a escala Liekert no SERVQUAL.

As entrevistas foram realizadas respeitando o tempo de partida de cada avião, não foram realizadas quando o horário de embarque estava próximo. A escolha de respondentes ocorria quando estes se apresentavam na fila de check-in no intervalo compreendido entre $1 \mathrm{~h} 20$ min e $1 \mathrm{~h}$ de antecedência de seu horário. As etapas de procedimento de pesquisa, assim como o desenvolvimento de metodologia são apresentadas na Figura 1.

FIGURA 1 - DESENVOLVIMENTO E ETAPAS DA METODOLOGIA.

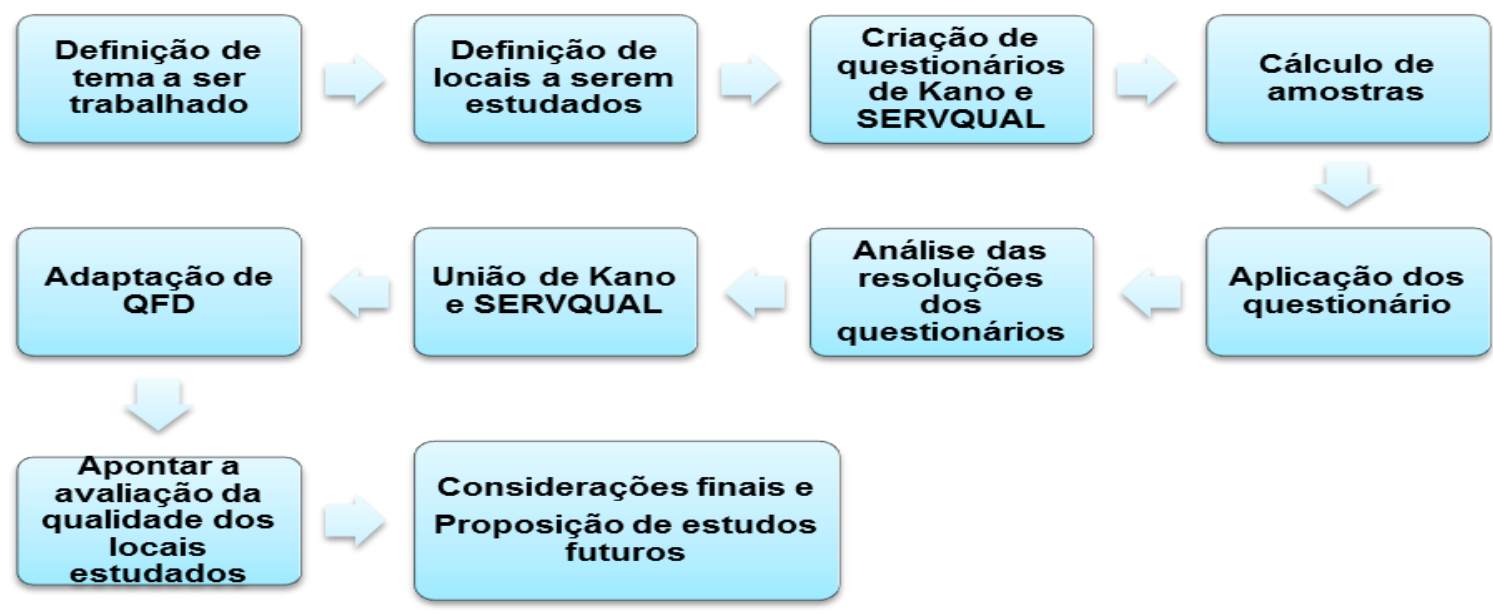

FONTE: Autores (2018).

A população utilizada como base para o cálculo de amostras foi à média de passageiros dos anos de 2015, 2016 e 2017. Em consequência da grande quantidade de pessoas no universo estudado e sua possível variação, deve-se realizar o cálculo de 
amostragem com o objetivo de alcançar parcela representativa da população. A equação sugerida por Ganga (2012) foi utilizada, sendo:

$$
n=\frac{Z_{\kappa}^{2}[p(1-p)] N}{Z_{\tilde{\omega}}^{2}[p(1-p)]+(N-1) C_{p}^{2}}
$$

- $Z \alpha=1,96$, pois representa intervalo de confiança de 95\%;

- $\mathrm{Cp}=0,05$, representando intervalo de confiança;

- $\mathrm{p}=0,5$ Proporção relativa à variável estudada;

- $\mathrm{N}=30116$ Tamanho da amostra (sendo a média do número de passageiros trafegando pelo aeroporto).

O número amostral encontrado foi de 380 , porém alcançou-se somente 278 questionários respondidos, não diminuindo o valor da pesquisa, em justificativa da proposição de utilização de diferentes ferramentas para o objetivo de qualidade sobre a óptica dos usuários.

\section{AEROPORTOS}

Neumayr (2016) coloca um aeroporto como sendo a principal porta de entrada do fluxo de pessoas, tanto nacionalmente quanto internacionalmente. Quando se trata de movimentos de médias e longas distâncias, o meio de transporte aéreo se torna preferencial, atuando não somente como ponto de ingresso a determinado local, mas também para egresso e distribuição de riquezas.

A ANAC (2017) - Agência Nacional de Aviação Civil expõe o desenvolvimento do setor aeroviário como grande impulsionador da economia do território brasileiro devido a peculiaridade da grande extensão territorial, os terminais agem como unidades de agregação e integração.

Aeroportos oferecem diversos serviços, desde os mais básicos que são: banheiros, assentos contando com porcentagem relacionada a pessoas obesas, gestantes, idosos, fraldário, existindo também os complementares (não influenciam na prestação 
do serviço, mas são pontos que geram valores ao mesmo) que são: lojas de souvenir, restaurantes, bancos ou caixas eletrônicos (YEH, 2003).

A ANAC (2014) - Agência Nacional de Aviação Civil considera o nível de percepção em relação ao serviço prestado por uma unidade aeroviária dependente da subjetividade de cada indivíduo, ou seja, a experiência vivida por cada passageiro irá diferenciar a sua percepção em relação à qualidade e condições dos componentes existentes.

\section{QUALIDADE}

A qualidade é a adequação ao uso, na qual se refere a duas visões. A primeira diz respeito ao produto que atende às demandas dos consumidores, em outras palavras, apresenta o desempenho do produto. Tal desempenho é fruto das particularidades do produto, ampliando a satisfação do usuário, dilatando sua disseminação no mercado. A segunda visão trata da falta de deficiências, as mesmas se checadas, resultam na insatisfação do usuário com o próprio bem tangível. Em contrapartida, restringem a repetição dos erros, de retrabalho, de desperdícios e até de inspeções (JURAN, 1989).

Para ocorrer compreensão de qualidade torna-se necessário apresentar um conjunto de conceitos de qualidade a partir dos principais nomes da temática, os chamados gurus.

No Quadro 1 se informa autores e suas conceituações sobre qualidade.

QUADRO 1 - CONCEITOS DE QUALIDADE DE ACORDO COM OS GURUS TEÓRICOS

\begin{tabular}{|c|c|}
\hline TEÓRICO & Definição \\
\hline CROSBY (1984) & $\begin{array}{c}\text { Qualidade é a necessidade de zero defeito e realizar o } \\
\text { serviço correto na primeira vez, evitando o retrabalho. }\end{array}$ \\
\hline ISHIKAWA (1986) & $\begin{array}{c}\text { Qualidade não significa só excelência ou outro } \\
\text { atributo de certo produto final. É na verdade o } \\
\text { objetivo final de uma companhia e é também o que os } \\
\text { públicos internos e externos esperam do produto. }\end{array}$ \\
\hline JURAN (1989) & Qualidade é adequação ao uso. \\
\hline
\end{tabular}

Continua ... 


\begin{tabular}{|c|c|}
\hline \multicolumn{1}{|c|}{ DEMING (1990) Continuação } \\
\hline FEIGENBAUN (1991) & Necessidade de redução de custos de produção \\
\hline SLACK (1993) & Foco no cliente e Sistema da qualidade \\
\hline PALADINI (2006) & Qualidade é sempre fazer o certo \\
\hline $\begin{array}{c}\text { Qualidade corretamente definida é aquela que } \\
\text { prioriza o público interno e externo. Isto mostra que a } \\
\text { qualidade é mais do que simples estratégias ou } \\
\text { técnicas estatísticas é antes uma questão de decisão, } \\
\text { que reflete em políticas de funcionamento da } \\
\text { organização. }\end{array}$ \\
\hline
\end{tabular}

FONTE: Autores (2018).

Segundo Carpinetti (2012), a expressão qualidade é amplamente difundida junto à sociedade e também nas organizações, contudo, considerando seu subjetivismo, manifestaram-se diversas compreensões para esclarecer o termo qualidade, prevalecendo nas últimas décadas, na qual seguramente estampa a futura tendência, é o conceito que qualidade se concilia com satisfação dos clientes. Enfatiza suma importância reconhecer que os serviços não se caracterizam como atuações meramente marginais, mas sim, parte suplementar da sociedade. Na qual configura a força indispensável de transformação da sociedade em direção a uma economia globalizada. Os serviços estão presentes em várias situações, em uma consulta ao médico, uma ida ao restaurante, uma livraria, isto é, os serviços se tornaram parte do cotidiano das pessoas.

\section{FERRAMENTAS E APLICAÇÕES}

Nesta seção constam as ferramentas individualmente, tendo em cada tópico uma breve revisão teórica e o resultado de aplicação. A metodologia aplicada segue a sequência: SERVQUAL, Modelo de Kano e QFD.

\subsection{SERVQUAL}

Por meio do modelo tradicional dos "gaps", Zeithaml, Parasuraman e Berry (1990) formularam a Escala Servqual para verificação das percepções dos clientes sobre 
a qualidade de serviços. O modelo apresentado pelos autores afere as expectativas e percepções dos clientes no que tange a um serviço de qualidade.

Berry, Parasuraman e Zeithaml (2006) mencionaram acreditar que a qualidade identificada expressa um veredito global na qual o cliente cria a partir da excelência ou deficiência do serviço, correspondendo uma forma de atitude relacionada, mas não proporcional à satisfação, e que resulta de uma confrontação das expectativas com as percepções da execução do serviço.

Parasuraman, Zeithaml e Berry (1988) apontam cinco dimensões da qualidade com intuito de montar uma ferramenta de pesquisa chamada SERVQUAL, que compreende duas seções. A primeira apresenta 22 itens e registra as expectativas dos clientes em relação a um determinado serviço. A segunda também detém os mesmos 22 itens, mas é voltada à avaliação do desempenho do serviço percebido pelo usuário, a partir das respostas dos entrevistados nas duas seções têm-se os gaps ou lacunas da qualidade, adquiridos pelo cálculo de expectativa menos a percepção. No quadro 2 se expõe as cinco grandezas da qualidade de serviços, estando presentes as suas respectivas definições.

QUADRO 2 - AS CINCO DIMENSÕES DA QUALIDADE POR PARASURAMAN, ZEITHAML E BERRY

\begin{tabular}{|c|l|}
\hline Dimensões & \multicolumn{1}{|c|}{ Definições } \\
\hline Tangibilidade & $\begin{array}{l}\text { Facilidades e aparência física das instalações, equipamentos, pessoal e } \\
\text { material de comunicação. }\end{array}$ \\
\hline Confiabilidade & Habilidade em fazer o serviço prometido com confiança e precisão. \\
\hline Receptividade & $\begin{array}{l}\text { Disposição para ajudar o usuário e fornecer um serviço com rapidez } \\
\text { de resposta e prontidão. }\end{array}$ \\
\hline Garantia & $\begin{array}{l}\text { Conhecimento e cortesia do funcionário e sua habilidade em inspirar } \\
\text { confiança. }\end{array}$ \\
\hline Empatia & Cuidado em prestar atenção individualizada aos usuários. \\
\hline FONTE: Param
\end{tabular}

FONTE: Parasuraman et al. (1988).

A partir da ferramenta estabelecida - SERVQUAL, tem-se a avaliação da qualidade de um serviço, por um consumidor, análise realizada por meio da diferença entre a expectativa e o julgamento pessoal por parte do cliente quanto ao desempenho do serviço (MIGUEL, 2004). 
Os dados apresentados são provenientes do questionário SERVQUAL no local de estudo para aplicação da abordagem metodológica proposta, todos os valores apresentados nas tabelas referentes à SERVQUAL foram retirados a partir de média simples, ou seja, somando-se os valores e dividindo pelo tamanho da amostra. SERVQUAL inicia-se com a necessidade de reconhecimento de grau de importância segundo os usuários, as opiniões são expressas em valores pela Tabela 1 - esta apresenta a média considerada pelo número amostral, exigindo-se a cada respondente a alocação do total de 100 pontos em distribuição optativa.

\section{TABELA 1 - MÉDIA DAS DIMENSÕES DA QUALIDADE DO QUESTIONÁRIO SERVQUAL}

\begin{tabular}{ccc} 
Dimensão & Definições & Média \\
\hline Tangibilidade & Localização, instalações físicas (equipamentos e & 27,25 \\
materiais). & 19,92 \\
Confiabilidade & Prestação de serviço de maneira confiável e no tempo & certo \\
Presteza & Prontidão do colaborador em auxiliar o cliente & 15,08 \\
Segurança & Transparecer conhecimento técnico de sua função & 25,50 \\
Empatia & Cuidado individual para com o cliente & 12,25 \\
\hline
\end{tabular}

FONTE: Pesquisa de campo (2018).

Na Tabela 1, verifica-se a dimensão Tangibilidade com maior média no referente ao grau de importância, com valor de 27,25. Na segunda posição ficou Segurança $(25,50)$ e na sequência: Confiabilidade $(19,92)$, Presteza $(15,08)$ e Empatia $(12,25)$. As dimensões que alcançaram maiores resultados representam maior importância aos clientes que utilizaram os serviços do aeroporto.

O valor de importância exibido pela Tabela 2 relata a classificação de importância das duas dimensões mais importantes, valores provenientes de alocação da opinião dos entrevistados de importância sobre as categorias da qualidade, utilizando os mesmos parâmetros contidos na Tabela 1.

TABELA 2 - PERCENTUAL DE IMPORTÂNCIA DAS DIMENSÕES DA QUALIDADE DO QUESTIONÁRIO SERVQUAL

Classificação

Dimensão

Percentual de importância

\begin{tabular}{ccc}
\hline Mais importante & Tangibilidade & $47,66 \%$ \\
Segunda mais importante & Segurança & $43,35 \%$ \\
\hline
\end{tabular}

FONTE: Pesquisa de campo (2018). 
A partir do valor percentual de importância da Tabela 2, verifica-se a mais importante aos olhos do cliente sendo a dimensão Tangibilidade, tendo como segunda mais importante a Confiabilidade, continuando com Tangibilidade como a representante de maior peso para os clientes entrevistados no aeroporto.

A Tabela 3 manifesta os resultados adquiridos na aplicação do questionário da metodologia de SERVQUAL, onde os respondentes tinham a disposição para elencar as notas à escala Likert nas medidas de 1 a 5 , referente ao grau de concordância e discordância, onde: 1 - Discordo totalmente (DT); 2 - Discordo Parcialmente (DP); 3 Indiferente (I); 4 - Concordo Parcialmente (CP); 5 - Concordo totalmente (CT), sendo necessária a modificação dos valores da escala para: 1 - Insuficiente; 2 - Regular; 3 Bom; 4 - Muito bom; 5 - Excelente, visando entendimento por parte do entrevistado. Os gaps $^{l}$ são os resultados alcançados a partir do cálculo da subtração da expectativa pela percepção, a Tabela 3 apresenta os valores médios.

TABELA 3 - RESULTADO DA APLICAÇÃO DO QUESTIONÁRIO SERVQUAL

\begin{tabular}{|c|c|c|c|}
\hline Itens & Percepção & Expectativa & Gaps \\
\hline 1. Equipamentos conservados e modernos. & 3,15 & 4,31 & $-1,16$ \\
\hline $\begin{array}{l}2 \mathrm{O} \text { ambiente físico e as instalações são limpos e } \\
\text { agradáveis. }\end{array}$ & 3,87 & 4,53 & $-0,66$ \\
\hline $\begin{array}{l}\text { 3. A equipe técnica com boa aparência e } \\
\text { vestuários bem cuidados, de acordo com as } \\
\text { características do ambiente de trabalho. }\end{array}$ & 3,99 & 4,07 & $-0,08$ \\
\hline 4. Boa localização e fácil acesso. & 2,54 & 4,45 & $-1,91$ \\
\hline $\begin{array}{l}\text { 5. Informação precisa sobre data e hora de } \\
\text { quando os serviços serão prestados }\end{array}$ & 3,59 & 4,74 & $-1,15$ \\
\hline $\begin{array}{l}\text { 6. Envolvimento dos administradores com a } \\
\text { qualidade e melhoria dos serviços prestados }\end{array}$ & 2,83 & 4,17 & $-1,33$ \\
\hline $\begin{array}{l}\text { 7. Realização de procedimentos e serviços } \\
\text { apenas uma vez e de forma correta }\end{array}$ & 3,11 & 4,05 & $-0,94$ \\
\hline $\begin{array}{l}\text { 8. Execução de serviços no prazo e tempo } \\
\text { prometidos }\end{array}$ & 3,96 & 4,87 & $-0,91$ \\
\hline $\begin{array}{l}\text { 9. Transmissão de informações necessárias de } \\
\text { forma confiável e segura }\end{array}$ & 3,14 & 3,83 & $-0,69$ \\
\hline $\begin{array}{l}\text { 10. Funcionários com boa vontade em atender } \\
\text { os clientes }\end{array}$ & 3,42 & 4,13 & $-0,71$ \\
\hline $\begin{array}{l}\text { 11. Funcionários apresentam-se com } \\
\text { disponibilidade e prontidão em atender os } \\
\text { clientes }\end{array}$ & 3,17 & 3,83 & $-0,66$ \\
\hline $\begin{array}{l}\text { 12. Durante a prestação de serviços a equipe } \\
\text { técnica passa confiança }\end{array}$ & 3,58 & 4,17 & $-0,59$ \\
\hline $\begin{array}{l}\text { 13. Funcionários são corteses e educados com os } \\
\text { usuários. }\end{array}$ & 3,53 & 4,56 & $-1,03$ \\
\hline
\end{tabular}

\footnotetext{
${ }^{1}$ Lacuna existente entre o desejo do cliente e o que ele recebe, ou seja, gap = Expectativa - Percepção.
} 
...Continuação.

14. Os funcionários possuem o conhecimento necessário para execução dos serviços.

15. A equipe de funcionários dá atenção personalizada ao cliente.

16. A equipe de funcionários possui

conhecimento para responder as perguntas dos

clientes.

17. Existência de procedimentos padronizados.

18. Os funcionários são atenciosos e procuram resolver todos os problemas dos usuários.

19. O aeroporto funciona em horários adequados aos seus clientes.

20. A comunicação (internet, telefones) é de fácil compreensão e utilização pelos clientes.

21. Existência de priorização dos interesses do cliente.

22. Os funcionários entendem as necessidades especificas dos usuários.

$\begin{array}{lll}3,51 & 4,25 & -0,74 \\ 3,42 & 4,17 & -0,75 \\ 3,67 & 4,11 & -0,44 \\ 2,58 & 3,83 & -1,25 \\ 3,58 & 4,17 & -0,58 \\ 3,37 & 3,92 & -0,55 \\ 3,25 & 4,33 & -1,08 \\ 3,1 & 4,13 & -1,03 \\ 2,47 & 3,98 & -1,51\end{array}$

FONTE: Pesquisa de campo (2018).

O Gap da questão número 4 foi o que teve o maior índice, denotando sua alta taxa na diferença entra a expectativa do serviço prestado e seu real desempenho, a pergunta de número 4 foi destinada à localização e ao fácil acesso ao terminal aeroviário.

É perceptível todos os questionamentos tendo como resultado valores negativos nos gaps, reforçando a ideia de que o aeroporto estava oferecendo serviços que não se encaixavam com as expectativas dos usuários ali presentes.

Foram colocados em ordem decrescente os três (três) pontos com maiores valores negativos, sendo um aspecto referente à Tangibilidade (questão 4), um à Empatia (questão 22) e um à Presteza (questão 6).

A partir dos Gaps, tornou-se perceptível o aeroporto não possuir boa localização e o fácil acesso que viesse a atender as expectativas dos usuários, resultando em uma perspectiva negativa, ou seja, a satisfação percebida foi frustrada pela identificação das reais condições do terminal aeroviário, no que tange a sua localização. Outra expectativa não atendida esteve relacionada ao treinamento dos funcionários, deixando a desejar no intuito de não atender as necessidades dos clientes, prejudicando a imagem do terminal de modo a gerar a decepção e o desgosto pelo serviço. E por fim, mas não menos relevante, segundo a ótica dos passageiros os administradores do aeroporto deviam estar mais engajados em proporcionar um serviço de qualidade aos clientes. 
Para a análise devem ser considerados só os elementos críticos que são representados pelo sinal negativo, na tabela 3 todos os aspectos analisados foram considerados críticos, devendo-se então priorizar os maiores valores negativos, admitindo que nestes se concentrem os maiores desníveis entra a realidade e a expectativa.

\subsection{MODELO DE KANO}

Noriaki Kano no ano de 1984 desenvolveu o método ou modelo de qualidade atrativa e obrigatória, popularmente conhecido como Modelo de Kano. Onde propôs relação da satisfação e do desempenho não linear, classificando os atributos em: obrigatórios, unidimensionais, atrativos e posteriormente adicionados os neutros e reversos. É considerada a relação existente de não linearidade entre desempenho e satisfação, existe a distinção de todos os atributos que estejam presentes em serviços ou produtos que irão gerar satisfação (TONTINI, 2008).

Löfgren (2005) discorre o objetivo do método de Kano, sendo a análise da percepção do cliente em relação aos pontos que tangem a qualidade, verificando a possibilidade de melhorias, possibilitando ter perspectivas diferentes em um mesmo objeto de estudo, auxiliando na classificação e priorização de necessidades dentro de um produto - Serviço ou Bem.

Tontini e Sant'ana (2007) acrescentam o foco de importância do consumidor pelos atributos, sendo em ordem decrescente: obrigatório, unidimensional, atrativo e neutro, porém para utilizar esta ferramenta como apoio na tomada de decisão deve-se compreender sua realidade, seu âmbito.

Pedrosa (2015) e Tontini (2008) informam sobre a definição de cada quesito presente na metodologia criada por Noriaki Kano, apresentando sua relação de ausência e presença no serviço oferecido a demanda, estes esclarecimentos estão evidenciados pelo Quadro 3. 
QUADRO 3 - DEFINIÇÃO E RELAÇÃO DE PRESENÇA E AUSÊNCIA DOS ATRIBUTOS DO MODELO DE KANO

\begin{tabular}{|c|c|c|c|}
\hline Atributos & Definiçães & Presença & Ausência \\
\hline Obrigatório & Atributo que tem seu comparecimento obrigatório. & $\begin{array}{c}\text { Não } \\
\text { Insatisfação }\end{array}$ & Insatisfação \\
\hline Unidimensional & $\begin{array}{c}\text { Este requisito apresenta a relação de quanto maior for seu } \\
\text { desempenho, irá influenciar proporcionalmente na } \\
\text { satisfação do cliente, e seu contrário é verdadeiro, ou seja, } \\
\text { quanto menor for seu desempenho mais gradativo será a } \\
\text { diminuição da satisfação. }\end{array}$ & Satisfação & Insatisfação \\
\hline Atrativo & $\begin{array}{c}\text { Atributos que trazem mais satisfação para o cliente além do } \\
\text { esperado, ou seja, é o diferencial de determinado produto, } \\
\text { que irá gerar sua diferenciação no mercado. }\end{array}$ & Satisfação & $\begin{array}{c}\text { Não } \\
\text { insatisfação }\end{array}$ \\
\hline Neutro & $\begin{array}{c}\text { Não gera satisfação ou insatisfação, não é um item que trará } \\
\text { onus ou bônus ao sistema. }\end{array}$ & $\begin{array}{c}\text { Não } \\
\text { insatisfação }\end{array}$ & $\begin{array}{c}\text { Não } \\
\text { insatisfação }\end{array}$ \\
\hline Reverso & Item quando apresentado gera insatisfação. & Insatisfação & Satisfação \\
\hline
\end{tabular}

FONTE: Elaborado a partir de Pedrosa (2015) e Tontini (2008).

As respostas adquiridas pela aplicação do questionário de Kano deram origem a Figura 2, expressando graficamente as categorizações de cada item - os mesmos 22 presentes na Tabela 3, verificando a falta de uniformidade de respostas, ou seja, diferentes categorias a um mesmo tópico.

FIGURA 2 - REPRESENTAÇÃO GRÁFICA DAS RESPOSTAS DO MODELO DE KANO

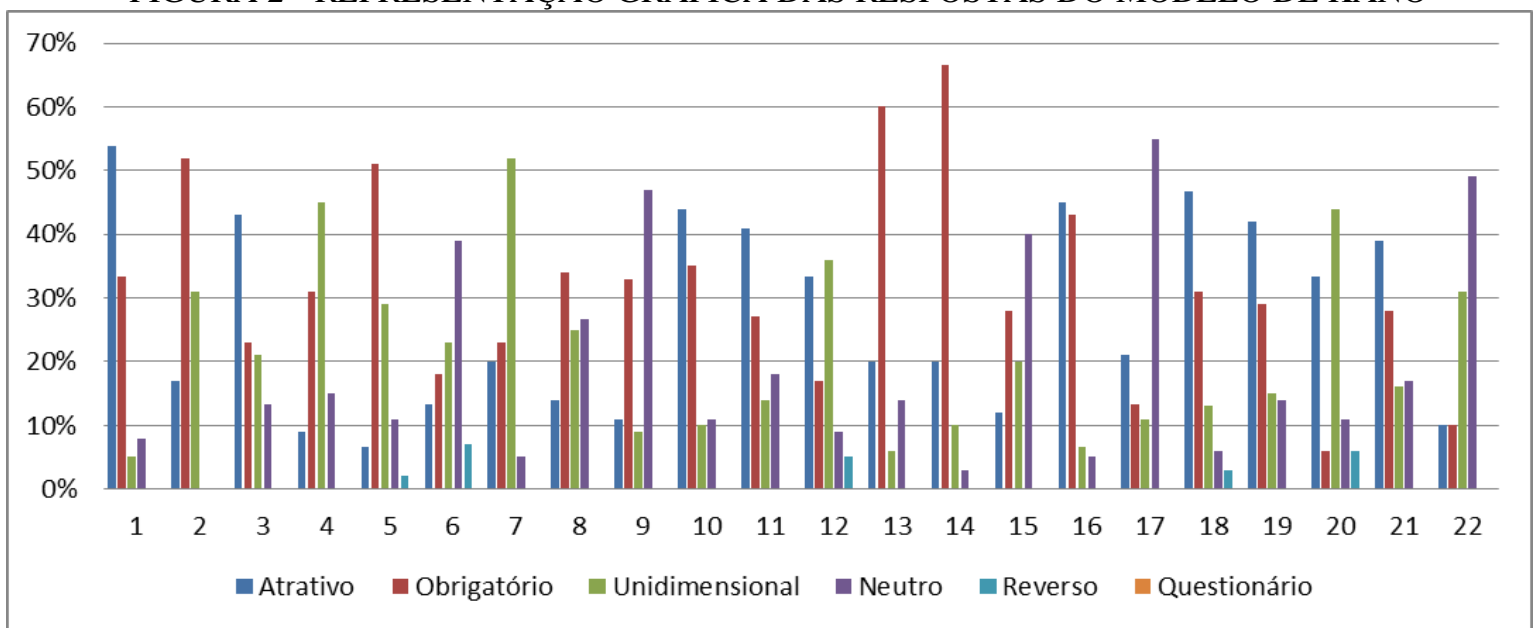

FONTE: Pesquisa de campo (2018).

Estão apresentados na Figura 2 todos os itens que faziam parte do questionário com suas respectivas classificações para com os atributos do modelo de Kano, na presente pesquisa foram priorizados como dados a serem tratados, apenas as categorias Obrigatório e Unidimensional. Diante disso tem-se: 


\section{- Obrigatório:}

2: A questão de número 2 faz referência ao fato de manter as dependências do terminal aeroviário limpas e conservadas, fator obrigatório a qualquer passageiro que procura ser bem recebido e quer fazer de sua espera um ato confortável e com totais chances de lhe satisfazer.

5: O item obrigatório de número 5 é referente à precisão com que os horários e datas são informados aos usuários, ponto primordial no que tange a transmitir um serviço de confiança, trazendo mais segurança a cada passageiro.

8: A questão presente faz alusão à confiabilidade que o aeroporto oferece aos usuários, fornecer os serviços no prazo e tempo prometidos é sem dúvida um aspecto de peso, quando se trata de um terminal aeroviário com vários voos e a necessidade de transmitir informações precisas.

13: Funcionários corteses e solícitos é um fator que gera satisfação a qualquer tipo de cliente e não podia ser diferente em um ambiente no qual a obtenção desses serviços é o fator chave, gerando fidelidade e confiança por parte dos passageiros.

14: O item 14 é destinado a competente capacitação dos vários funcionários dentro do terminal, possuindo conhecimento necessário para desempenhar as mais variadas funções, transmitindo segurança e comodidade, no sentido de não gerar retrabalho, levando ao desgosto e a frustação dos clientes.

Os pontos Obrigatórios englobaram principalmente aspectos que estão diretamente ligados com o treinamento correto dos funcionários, tais como: sendo ao fornecer com precisão os horários dos voos, no prazo e tempo prometidos anteriormente, possuir conhecimento necessário para efetuar sua função, todos esses fatores evidenciam a procura dos usuários por serviços corretamente desempenhados de modo a atender todas as expectativas dos mesmos.

- Unidimensional:

4: A presente questão é destinada à localização do aeroporto, ou seja, para os passageiros quanto mais acessível seja o terminal, considerando o tempo e a praticidade em se chegar no estabelecimento, mais satisfatório será.

7: O item de número 7 é referente ao de execução dos serviços corretamente da primeira vez que foi solicitado, não gerando a necessidade de se repetir os mesmos processos, ocasionando na perda de tempo e no aumento da insatisfação da clientela. 
12: O questionamento 12 está relacionado ao fato dos colaboradores do terminal transmitirem confiança nos serviços que estão sendo prestados naquele momento, de modo a aumentar o nível de qualidade percebida por parte do cliente.

20: O tópico 20 refere-se à comunicação entre ambas as partes envolvidas, seja por telefone ou internet, seja totalmente compreendida e esteja disponível para os passageiros na hora que demandarem.

Os tópicos unidimensionais se caracterizam pela concordância direta, isto é, quanto melhor for o serviço ali prestado, maior será a satisfação dos clientes, dessa maneira, ficou perceptível a indispensabilidade de um terminal bem localizado e de fácil acesso, a capacitação correta dos colaboradores, item presente também nos quesitos obrigatórios e uma estável comunicação entre o terminal e seus passageiros, esses fatores mostraram que a satisfação dos usuários do aeroporto de Marabá seria maior se todos os pontos informados anteriormente fossem disponibilizados da melhor forma possível.

\section{APLICAÇÃO DA INTEGRAÇÃO DO MODELO DE KANO, SERVQUAL E QFD}

Os atributos obrigatórios são em referência a mão de obra tendo atenção e cuidados com os clientes, e a necessidade de uma gestão participativa. Isto se deve ao fato de que os usuários percebem a importância do contato com o colaborador, pois estes itens são considerados substanciais para o desempenho do serviço prestado. Os atributos unidimensionais identificados estabeleceram a necessidade de cumprimento de horários que deve existir, assim como exercer todas as atividades no prazo correlato.

Com a finalidade de distinguir os principais atributos realizou-se priorização, com objetivo em realizar análise dos itens possuindo os maiores gaps e com classificação: Obrigatório e Unidimensional. Dispensando os itens categorizados como Atrativo, Neutro e Reverso. Pelo fato de o objeto de estudo ser o maior e único aeroporto em sua região e tendo como consequência a falta de concorrentes e desta forma tornando os serviços prestados nesses estabelecimentos como únicos e sem a 
possibilidade de escolha de outro com o desempenho igual ou superior por parte do usuário. Este processo teve como resultado a Tabela 4.

TABELA 4 - ELEMENTOS PRIORIZADOS

\begin{tabular}{ccc}
\hline Item & Gaps & Categorização Kano \\
\hline 2 & $-0,66$ & $\mathrm{O}$ \\
4 & $-1,91$ & $\mathrm{U}$ \\
5 & $-1,15$ & $\mathrm{O}$ \\
7 & $-0,94$ & $\mathrm{U}$ \\
8 & $-0,91$ & $\mathrm{O}$ \\
12 & $-0,59$ & $\mathrm{U}$ \\
13 & $-1,03$ & $\mathrm{O}$ \\
14 & $-0,74$ & $\mathrm{O}$ \\
20 & $-1,08$ & $\mathrm{U}$
\end{tabular}

Adotado pela fábrica Toyota, o QFD tem como seu objetivo: clientes satisfeitos, pois agrega valor no progresso de um produto. Esta ferramenta está ligada diretamente ao consumidor, pois coloca os requisitos dos clientes em harmonia com todas as etapas de produção, desde a pesquisa relacionando a demanda com o que será produzido, até o produto acabado, tendo qualidade, sendo importante método para desenvolver um produto (bem ou serviço), traduzindo os requisitos do cliente (CARNEVALLI; MIGUEL 2007; MIGUEL, 2008).

Pasquini (2013) e Cheng (2010) colocam o QFD sendo o método de desenvolvimento de qualidade dirigido a satisfazer o cliente. Esta ferramenta segue os seguintes passos para alcançar a meta principal relacionada ao bem-estar gerado ao consumidor, que são: organizar requisitos projetados e planejados; análise de mercado, definição relacionada à concorrência; reconhecer possíveis pontos de controle no shop floor. O método é decomposto em quatro partes ou fases: casa da qualidade, planejamento dos componentes, planejamento dos processos e planejamento da produção. As quatro fases estão presentes na Figura 3. 
FIGURA 3 - REPRESENTAÇÃO GRÁFICA DAS FASES DO QFD

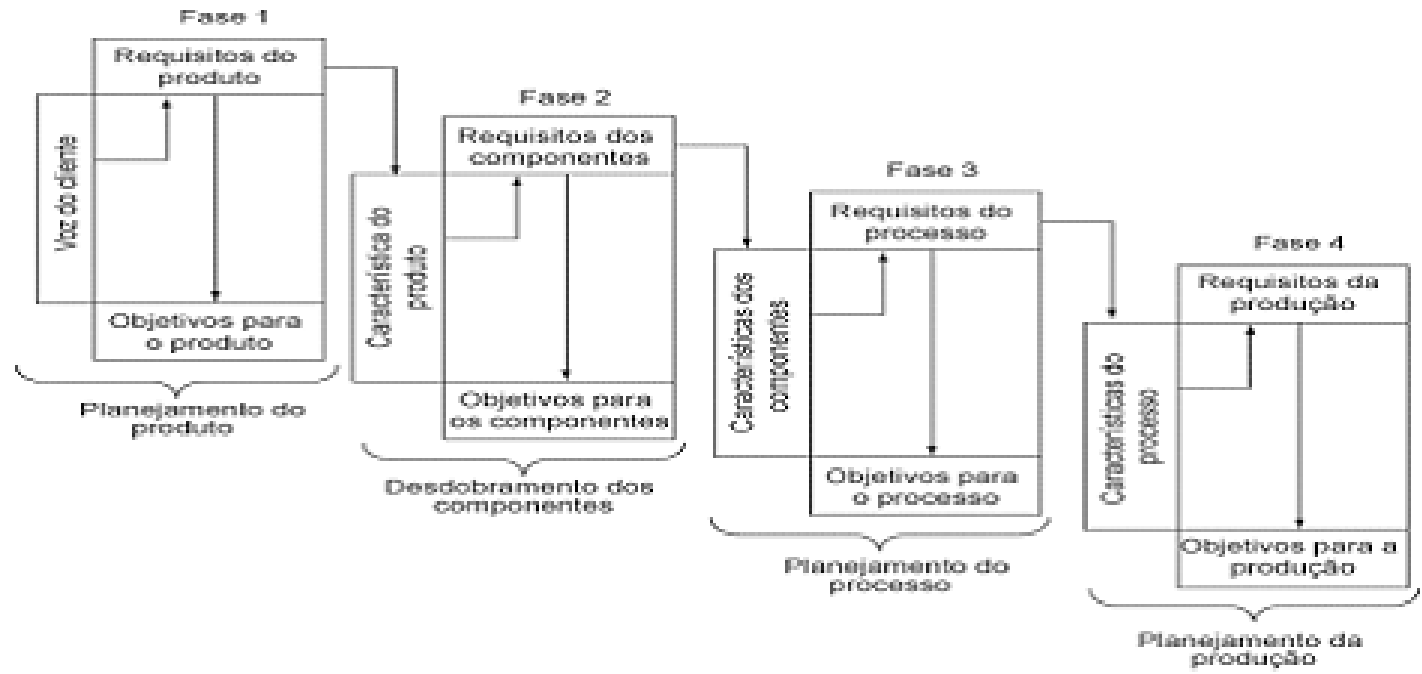

FONTE: Rosa (2013).

$\mathrm{Na}$ literatura estão presentes trabalhos que utilizam a união de ferramentas e metodologias, para alcançar exatidão em relação a um problema. $\mathrm{O}$ mesmo ocorre com SERVQUAL, Kano e QFD sendo combinados em diferentes setores dos serviços (MAIA, 2013).

O presente trabalho teve como intuito alcançar a capacidade máxima de cada ferramenta, realizando todos os passos individuais necessários, ou seja, verificar os maiores gaps do serviço no aeroporto, caracterizar e classificar os atributos a partir da opinião dos clientes do aeródromo, utilizar os dados adquiridos para análise e desta forma traduzir os anseios/necessidades em requisitos, respectivamente, utilizando em cada etapa descrita, SERVQUAL, Kano e QFD.

SERVQUAL e Kano utilizam questionários, como existe etapa referente à união das respostas de ambos, se fez necessário utilizar mesma quantidade e nomenclatura de questões para ambas as ferramentas e desta forma conterem o mesmo número de atributos no momento da integração, ocorrendo igualdade de parâmetro.

A casa da qualidade da metodologia QFD foi criada com dados de preenchimento originados das Tabelas 1,2, 3 e 4. O lugar representativo aos requisitos do cliente foi preenchido pelos gaps do SERVQUAL, e por Kano com suas categorizações.

Para qualificação dos atributos de Kano no QFD foi realizada a seguinte analogia de pontuação: Unidimensional com valor de 2 pontos por serem atributos que 
apresentam linearidade da qualidade e os Obrigatórios com valor de 1 ponto, pois devem ser ofertados aos clientes inevitavelmente.

O grau de importância referente a cada ponto foi atrelado com base na dimensão a que este pertencia (tangibilidade, credibilidade, presteza, segurança e empatia), esta pesquisa utilizou a pontuação de Cheng (2010) para ponderar o âmbito mais importante em 5, o segundo mais importante em 3 e os demais em 1.

Segundo a metodologia do QFD apresentada por Cheng (2010) os espaços referentes a características da qualidade devem ser preenchidos por uma equipe, contendo conhecimento sobre a área estudada, desta maneira foi necessária a entrevista com 1 gerente de agência de passagens aéreas do município do local de estudo, pois este era um indivíduo que estava inserido dentro do âmbito pesquisado, mas não tinha ligação forte com o aeroporto. Após a reunião foi possível realizar o preenchimento das lacunas.

Ainda era necessária a matriz de correlação, para ser preenchida utilizou-se os métodos de Cheng (2010) com o apoio do gestor da agência de turismo em responder e avaliar em conjunto 3 perguntas e a partir das respostas realizar a correlação:

- Até onde a característica da qualidade avalia o atendimento à qualidade exigida?

- Como as características da qualidade afetam as qualidades exigidas?

- Como as qualidades exigidas são afetadas pelas características da qualidade?

As correlações receberam os valores a partir de Cheng (2010) de 9 para correlações fortes, 3 para correlações médias, 1 para correlações fracas e nenhuma pontuação quando não houvesse nenhuma correlação. Deve-se utilizar símbolos prédeterminados ou cores para esta representação, no trabalho se utilizou cores, sendo vermelha a correlação forte, verde a média e azul a fraca. Ao final das classificações em pontos deu-se início ao cálculo do grau de importância total, ou seja, a multiplicação entre: o grau de importância do cliente, na primeira coluna a esquerda da casa da qualidade, o Gap e seu respectivo atributo do modelo de Kano, que variou entre 2 e 1.

O peso absoluto é adquirido pela multiplicação entre o grau de importância total e a sua respectiva correlação (forte $=9$, média $=3$, fraca $=1$ ), os valores foram somados verticalmente e desta forma obteve-se o "peso absoluto" para cada característica, seguido do "peso relativo" - o "peso absoluto" de determinada característica dividido 
pela soma de todos os pesos absolutos, facilitando na classificação das características mais requisitadas pelos usuários. O QFD do aeroporto é apresentado pela Figura 4, exibindo as dimensões cujos tópicos apresentaram-se como unidimensionais ou obrigatórios e seus gaps negativos.

FIGURA 4 - QFD DO AEROPORTO

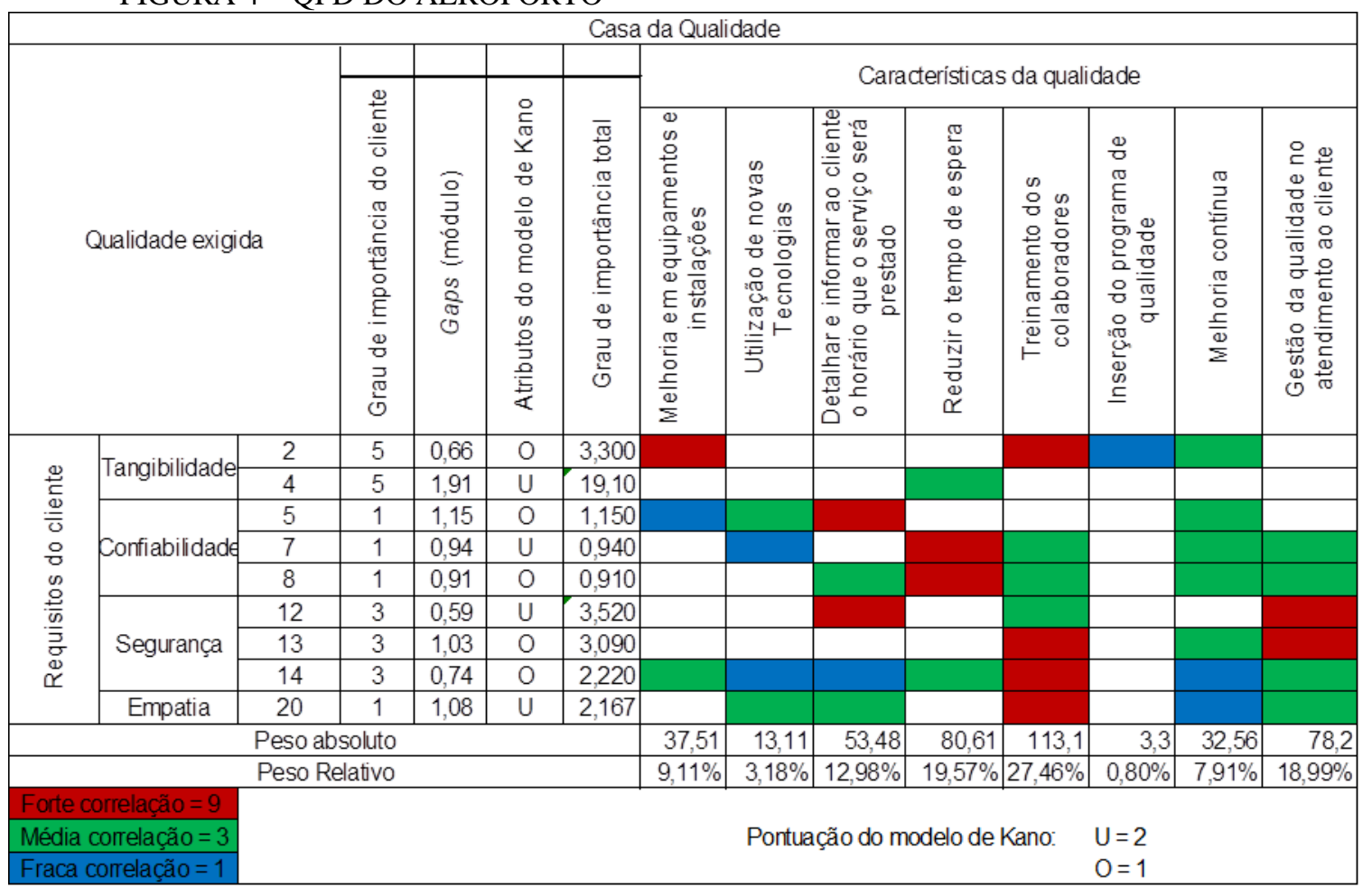

FONTE: Pesquisa de campo (2018).

$\mathrm{Na}$ categoria dos pesos absolutos na Figura 3, ficaram explícitos todos os requisitos demandados pelos clientes, características como: Treinamento dos colaboradores, Reduzir o tempo de espera e Gestão da Qualidade no atendimento ao cliente, atingindo números como: 113,1, 80,61 e 78,2, respectivamente, as três mais importantes características segundo os requisitos dos usuários.

O treinamento dos colaboradores é de suma importância, visto que em um terminal aeroviário, onde o tempo é rigidamente utilizado: na definição dos horários de voos, na realização do check-in, no despacho de malas e entre outros. Os colaboradores devem estar bem treinados para oferecer um serviço rápido e preciso, não afetando diretamente o serviço prestado, evitando possíveis estresses por parte dos clientes e consequentemente a queda de movimentação naquele estabelecimento prejudicando também todas as companhias aéreas que necessitam do consumidor. 
Com a utilização do QFD constatou-se a forte correlação de redução do tempo de espera com os requisitos dos clientes, de modo que os usuários buscam não permanecerem muitas horas aguardando para utilizarem os serviços de um terminal aeroviário evitando possíveis reclamações e desgaste dos mesmos.

A gestão da qualidade no atendimento ao cliente ocupou o terceiro lugar nas características mais importantes com relação aos requisitos dos usuários, ressaltando a alta demanda por serviços de qualidade, ou seja, que atendam as expectativas dos clientes favorecendo no aumento dos níveis de satisfação.

\section{CONSIDERAÇÕES FINAIS}

O sucesso das organizações depende das decisões estratégicas, buscando entender o crescente desejo da população por serviço de qualidade, para haver o equilíbrio entre desempenho do empreendimento e satisfação dos clientes, a utilização de variadas ferramentas faz-se necessária. Partindo-se deste ponto no trabalho se buscou utilizar três metodologias diferentes para análise de como cada aeroporto pode alcançar satisfação no seu usuário, ou seja, como contribuir para a melhoria dos serviços prestados, pois se entende a complementação que uma ferramenta tem com a outra.

Por meio da aplicação dos dois questionários, SERVQUAL e o modelo de Kano e em seguida a criação da casa da qualidade no terminal aeroviário considerou-se terem ficado claros os pontos de maior decepção dos usuários para com os serviços prestados, permitindo encontrar as características da qualidade que estão diretamente relacionadas, como: Treinamento dos colaboradores, Reduzir o tempo de espera e a Gestão da Qualidade no atendimento ao cliente, características essas que necessitam de atenção por parte dos gestores do aeroporto no que tange a tomada de decisão, para um aumento de desempenho e competitividade em razão da satisfação dos clientes.

Foram encontrados aqueles considerados os principais pontos a serem melhorados em aeroportos, para estes alcançarem qualidade segundo a óptica de sua demanda, porém posteriormente aos ajustes realizados nos principais gaps, deve-se ocorrer a necessidade de avaliação novamente, para reflexão de quais serão os problemas com esta atualização na base de dados. 


\section{REFERÊNCIAS}

ANAC. Aerodromos 2017. Disponível em:

<http://www.anac.gov.br/Anac/assuntos/setor-regulado/aerodromos>. Acesso em: $18 / 02 / 2017$.

ANAC. Planejamento Integrado de Investimentos da Infra-Estrutura Aeronáutica. Comando de Aviação Civil, Subdepartamento de Infra-Estrutura relatório 2010. Disponível em: <www2.anac.gov.br/biblioteca/iac/IAC5001.pdf>. Acesso em: $15 / 02 / 2017$.

ASCHER, F. Os novos princípios do urbanismo. São Paulo: Romano, 2010.

BERRY, L. L.; PARASURAMAN, A.; ZEITHAML, V. A. Um Modelo Conceitual de Qualidade de Serviços e suas Implicações para a Pesquisa no Futuro. RAE - Revista de Administração de Empresas, v. 46, n. 4, p. 96-107. Outubro /dezembro. 2006.

CARPINETTI, L. C. R. Gestão da qualidade: Conceitos e técnicas. 2. Ed. São Paulo: Atlas, 2012.

CARNEVALLI, J. A.; MIGUEL, P. A. C. Revisão, análise e classificação da literatura sobre o QFD - tipos de pesquisa, dificuldades de uso e benefícios do método. Gestão e Produção, v. 14, n. 3, p. 557-579. 2007. Disponível em: <http://dx.doi.org/10.1590/S0104-530X2007000300011>.

CHENG, L. C.; MELO FILHO, L. D. R. QFD: desdobramento da função qualidade na gestão de desenvolvimento de produtos. 2. ed. São Paulo: Blucher, 2010.

CROSBY, P. B. Qualidade é investimento. Rio de Janeiro: José Olympio Editora, 1984.

DEMING, W. E. Qualidade: a revolução da administração. São Paulo: Marques Saraiva, 1990.

FEIGENBAUN, A. V. Total Quality Control. 3rd ed. New York: McGraw Hill Book Company, 1991.

GANGA, G. M. D. Trabalho de Conclusão de Curso (TCC) na engenharia de produção: um guia prático de conteúdo e forma. São Paulo: Atlas, 2012.

GÜlleR, M., GÜLlER, M. Del Aeropuerto a La Ciudad-Aeropuerto. Barcelona: Editorial Gustavo Gilli, 2002.

IBGE (2018). Pesquisa Mensal de Serviços. Disponível em: $<$ https://www.ibge.gov.br/estatisticas-novoportal/economicas/servicos/9229-pesquisamensal-de-servicos.html?=\&t=resultados>. Acesso em: 11/02/2018. 
ISHIKAWA, K. TQC, Total Quality Control: Estratégia e Administração da Qualidade. São Paulo: IMC Internacional Sistemas Educativos, 1986.

JURAN, J. M. Juran na liderança pela qualidade: um guia para executivos. São Paulo: Pioneira, 1989.

LOFGREN, M; WETTEL, L. Kano's Theory of attractive quality and packaging. Quality Management Journal, v. 12, n. 3, p. 7-20, 2005.

MAIA, M. C. de S. Uma abordagem para avaliação da satisfação dos clientes em empresas de serviços de saúde: Aplicação da integração dos modelos SERVQUAL, KANO e QFD. Dissertação de mestrado, faculdade de engenharia de produção, Universidade Federal do Pernambuco, Recife, PB, Brasil, 2013.

MIGUEL, P. A. C. Implementação do QFD para o desenvolvimento de novos produtos. São Paulo: Atlas, 2008.

NEUMAYR, A. A prestação de serviços em aeroportos: os modelos de mensuração da qualidade percebida pelos passageiros. Caderno de Estudos e Pesquisas do Turismo, v. 5, n. 6, p. 57-73, 2016.

PALADINI, E. P. Gestão da Qualidade: teoria e prática. 2. ed. São Paulo, 2006.

PARASURAMAN, A. SERVQUAL: A Multiple-Item Scale for Measuring Consumer Perceptions of Service Quality. Journal of Retailing, v. 64, p. 12-40, 1988.

PASQUINI, N. C. Desdobramento da Função da Qualidade (QFD) conceitos e aplicações. Revista qualidade emergente, v. 4, n. 2, 2013, p. 1-19.

PEDROSA, R. C. de V. Avaliação da qualidade em um serviço público de saúde com a aplicação do modelo de Kano e SERVPERF. Dissertação de mestrado, faculdade de engenharia de produção, Universidade Federal do Pernambuco, Recife, PB, Brasil, 2015.

SANTOS, B. de S. Globalização: Fatalidade ou Utopia? Porto: Edições Afrontamento, 2001.

SLACK, N. Vantagem competitiva em manufatura. São Paulo: Atlas, 1993.

SILVA, E. S. da.; SILVA, K. D.; OLIVEIRA, J. P. Q. de. A qualidade do atendimento ao turista: um comparativo entre duas cidades, São José da Coroa Grande (Pernambuco, Brasil) e Maragogi (Alagoas, Brasil). Revista Turismo e Sociedade, v. 11, n. 1, dez. 2018.

TONTINI, G.; SANT'ANA, A. J. Identificação de atributos críticos de satisfação em um serviço através da análise competitiva do gap de melhoria. Gestão e Produção, v. 14, n. 1, p. 43-54, 2007. Disponível em: <http://dx.doi.org/10.1590/S0104530X2007000100005>. 
TONTINI, G. Interaction of basic and excitement service attributes in customer satisfaction. Production, v. 18, n. 1, p. 112-124, 2008. Disponível em: <http://dx.doi.org/10.1590/S0103-65132008000100009>.

YEH, C. H. Evaluating passenger services of Asia-Pacific international airports. Transportation Research Part E, v. 39, n. 1, p. 35-48, 2003.

ZEITHAML, V. A.; PARASURAMAN, A.; BERRY L. L. Delivering Quality Service - Balancing Costumer Perception and Expectation. New York: The Free Press, 1990.

Recebido em: 12-09-2018.

Aprovado em: 12-10-2018.

Versão aprovada para publicação em: 31-03-2019. 